\title{
The Building Blocks of an Educational Esports League
}

\author{
Lessons from Year One in Orange County High Schools
}

\author{
Alexander Cho \\ Department of Informatics \\ University of California, Irvine \\ Irvine, CA USA \\ choa8@uci.edu
}

\author{
A.M. Tsaasan \\ Department of Informatics \\ University of California, Irvine \\ Irvine, CA USA \\ tsaasan@uci.edu
}

\author{
Constance Steinkuehler \\ Department of Informatics \\ University of California, Irvine \\ Irvine, CA USA \\ const@uci.edu
}

\begin{abstract}
In the 2017-2018 school year, 38 student teams from 25 high schools across Orange County, California, competed in weekly tournament play of the multiplayer arena battle video game League of Legends, culminating in a championship playoff in one of the first region-wide high school esports leagues in the US. Our team performed a formative evaluation of this League's first year, with special attention to logistical concerns as well as any potential alignments between esports and learning. Our team engaged student League players $(n=39)$ and teachers $(n=11)$ who managed their school's teams in focus groups and observation at six schools; we conducted focus groups with experienced player-coaches $(n=5)$ who supported teams, and one-on-one interviews with parents $(n=10)$. The paper identifies organic learning opportunities during league play such as critical analysis, communication, research skills, and social emotional learning; techniques to clearing administrative hurdles; and structural socioeconomic equity issues that the leadership team may not have anticipated. The paper incorporates recommendations for these areas and critically situates them for future deployment with attention to maximizing learning potential with equity and access for all.
\end{abstract}

\section{CCS CONCEPTS}

- Collaborative and Social Computing • Human Computer Interaction • Education • Computer Games

\section{KEYWORDS}

esports; Learning; Education; Social gaming; Youth; League of Legends; MOBA

\section{ACM Reference format:}

Alexander Cho, A.M. Tsaasan and Constance Steinkuehler. 2019. The Building Blocks of an Educational Esports League: Lessons from Year One

Permission to make digital or hard copies of all or part of this work for personal or classroom use is granted without fee provided that copies are not made or distributed for profit or commercial advantage and that copies bear this notice and the full citation on the first page. Copyrights for components of this work owned by others than the author(s) must be honored. Abstracting with credit is permitted. To copy otherwise, or republish, to post on servers or to redistribute to lists, requires prior specific permission and/or a fee. Request permissions from Permissions@acm.org.

FDG '19, August 26-30, 2019, San Luis Obispo, CA, USA

(c) 2019 Copyright is held by the owner/author(s). Publication rights licensed to ACM. ACM ISBN 978-1-4503-7217-6/19/08...\$15.00

https://doi.org/10.1145/3337722.3337738 in Orange County High Schools. In The Fourteenth International Conference on the Foundations of Digital Games Proceedings (FDG '19), August 26-30, 2019, San Luis Obispo, CA, USA. ACM, New York, NY, USA. 11 pages. https://doi.org/10.1145/3337722.3337738

\section{Introduction}

Esports, or organized competitive multiplayer videogaming, is swiftly growing in popularity. The League of Legends (Riot Games) World Championship counted 99.6 million viewers in 2018 [28], Forbes estimated it will soon be a billion-dollar industry [39], and US sports TV network ESPN recently secured a multiyear contract to broadcast Blizzard Games' Overwatch League [35]. Collegiate esports leagues are growing rapidly, and high school esports leagues are emerging worldwide [21, 12, 31, 46].

However, very little research to date has been conducted on esports, especially regarding esports' potential benefits or drawbacks in educational settings such as high schools or colleges. This is an imperative gap in the literature on digital games, especially since an adjacent body of research has found that social or multiplayer gaming can carry significant learning potential [53, 52]. Another related body of significant research finds that extracurricular, interest-based learning contexts can be prime venues for resilient learning [24]. Together these literatures suggest that, if leveraged correctly, esports in a school setting could carry significant potential for education.

The 2017-2018 school year saw the creation and inaugural season of the Orange County High School Esports League (now called the North America Scholastic Esports Federation) in the US. Thirtyeight (38) teams from 25 high schools across multiple districts in one region competitively played the online multiplayer team battle arena game League of Legends in a "Swiss-system"-style weekly tournament from January 2018 to April 2018. Quarterfinals, semifinals, and championship matches were held the weekends of April 14 and April 28 live in person at the Esports Arena in Santa Ana, CA. In League of Legends, players choose from over 100 different characters ("champions") with which they comprise two teams of five in a capture-the-base style online match. The game, a product of Santa Monica, CA-based Riot Games, had 100 million monthly players worldwide as of 2016 [41] and has a strong professional circuit. 
This paper is the summary of an ongoing formative evaluation of the League's first season. The goal of formative evaluation is to monitor an endeavor and provide feedback that can be used for improvement. This is typically different from "summative evaluation," which usually evaluates against a predefined benchmark [47, 14]. Accordingly, our research questions were:

- $\quad$ RQ1: What are major programmatic and operational successes and pain points in this first-year roll-out?

- $\quad$ RQ2: What are the existing and potential alignments between esports and learning?

In this paper, we present preliminary findings on both of these questions. These findings, while exploratory, document an implementation of competitive esports in high schools through a lens that highlights key logistical concerns; is focused on opportunities to activate learning potential across STEM, English/Language Arts, and social and emotional learning; and heeds situational context for equitable access. It is our hope that this paper can provide directional guidance from both a logistics and research standpoint, for audiences who are explicitly interested in on-the-ground logistics of esports in a high school setting and who are more broadly interested in the potential research alignments between this quickly growing video game category and education.

\section{Related Work}

We divide related work in two parts: a thumbnail sketch of current research on the potential of video games, especially social or collaborative video games, and learning; and an overview of relevant research on esports, its implications for esports in a learning setting, and potential tie-ins to documented outcome from "traditional" school sports programs.

\subsection{SEL and Literacy Learning Through Video Games}

Contemporary video games such as those used for esports are often social and cooperative. From a social and emotional learning (SEL) perspective, playing video games cooperatively with others can lead to widespread benefits by making players think helpful behaviors are valuable and commonplace [55]. They serve as a potent opportunity for socializing for teens and play an important role in the creation of teens' friendships - this is especially true for boys [38]. One psychological research overview suggested that video games may be able to train players in "adaptive regulation" for goal achievement [19]. Another study found that casual games such as puzzle games can improve mood and decrease stress [42].

One large EU study of youth ages 6-11 found that a high level of video game play was associated with high intellectual functioning, high overall school competency, decreases in peer relationship problems, and decreases in prosocial deficits [27]. In another large study, adolescents who played games with civic experiences (e.g., Guild Wars 2, an MMORPG, or massive multiplayer online roleplaying game) were more likely to be engaged in social and civic movements in their everyday lives [29]. There is a strong precedent in using legacy/analog gaming in educational settings, ranging from games such as chess for improved cognition [43] to intervening in SEL, such as using board games to develop emotional well-being in maladaptive boys [7]; games as "a 'social experiment' in which players must use self-regulation and social skill to play successfully with others." [23]; and a legacy of "supportive play" in early childhood development that may have benefits if extended throughout education [49, 40]. Games are "especially good at communicating relationships: digital games are most immediately about the direct relationship between the player's action or choices and their consequences” [2].

Video games "lie at the nexus of a complex constellation of literacy practice” [50, 51, 18], especially if understood from a "multiliteracy" perspective that accounts for the "multiplicity and integration of significant modes of meaning-making, where the textual is also related to the visual, the audio, the spatial, the behavioral ... particularly important in the mass media, multimedia, and in an electronic hypermedia” [54]. Massively-multiplayer online games, for example, have learning baked into their design and play: low-stakes failure-as-feedback, collecting data and analyzing it, activity-based collaboration, and more [53]. And, though an overview of "gamification" as learning is spaceprohibitive here, there is a long history in education literature of using games as an approach to teaching subject area content as well as skills such as communication, research, and analysis [26, 6, 44]. This literature suggests that esports, with its emphasis on intense teamwork, its high communicative demands, on-the-spot informed decision making, and collaborative postmortem analytics could carry similar potential for learning $21^{\text {st }}$-century learning.

\subsection{Esports and Learning}

Esports' roots go back to the 1990s, in which US and European gamers formed "clans" in the games Doom and Quake and the “Cyberathlete Professional League,” together with a simultaneous emergence in Korea of popular MMORPGs such as Lineage as well as the heavy adoption of competitive "real time strategy" games, such as StarCraft [56]. To date, however, there is little existing research on esports, especially as they relate to learning. esports can be thought of as an emerging constellation of cultural communities, moving well beyond the idea of simple disconnected "players" of a game and instead becoming nothing less than an "amalgamated cultural phenomenon" [48]. This refers to an entire infrastructure, from game developers to players to fans to media to "shoutcasters" (live audio commentators), and streaming platforms such as Twitch and audio platforms like Discord.

From a sociocultural perspective, the fundamental vehicle for learning in esports is this amalgam of interaction supported by the activities and tools orbiting competitive gaming. The infrastructure of esports supports competition, participatory community, and digitally-mediated social interactions. As the social gaming literature outlines above, this aspect of esports could support a rich arena for learning from an interest-based, informal, and peer-driven 
The Building Blocks of an Educational Esports League: Lessons From Year One in Orange County High Schools

perspective, mirroring the "Connected Learning" framework [25]. There may even be an equity intervention possible. We know that wealthy families are disproportionately pouring money into interest-based learning activities for their children as opposed to low-income families, a gap that widens each year [25]. Duncan states, "In many contemporary schools, students are afforded very little facility to reconfigure and restructure their learning materials (e.g., a low degree of ludic affordances) ... there is a stark difference between activities engaged upon within ad hoc online communities and the restrictions of many contemporary curricula” [9]. The recognition of an amplification of esports as an interestbased learning environment in schools, complete with its rich social networks and paratexts such as character literature and online communities, could enable educators to tap into some students' unrecognized "funds of knowledge" [32] of esports, engaging students who are in school via interest-based, informal learning simultaneously with content-area instruction [4].

Hamari and Sjöblom argue that the distinction between esports and more traditional sports may be blurrier than seems at first glance [20]. For example, esports can involve varying degrees of physicality [57] or, as one of our coaches describes later in this paper: League of Legends is "a feel game." As well, today's "traditional” sports often involve electronic/computer equipment of some kind, as "all elite athletes are, to varying degrees, profoundly technologized" [3]. If the difference between esports and "traditional sports" is simply "where the player or team activities that determine the outcomes of the sport/play are manifested," [20] it is possible that the well-documented positive outcomes of sports for young people in schools-improved self-esteem and social interaction [10], self-efficacy [8, 36] lower levels of depression [45], and even as social skills support for students with special needs such as ADHD [34]—could also be present in high school esports, if activated with these emphases.

Within ACM organizations, literature is beginning to emerge around these topics, though, as above, even arriving at a definition of what exactly constitutes esports is difficult [15]. In alignment with what literature cited above suggests about the benefits of social gaming, Freeman and Wohn interviewed esports players and concluded that the esports experience provided "emotional and esteem support," and also that these support functions “'bled' out into in-person interactions and relationships" [17]. However, this is in direct contrast to some esports' (deserved) reputation for being breeding grounds of toxic or disruptive behavior [30, 1]. Any esports endeavor at the high school level will have to systematically address this tendency in order to maximize the pro-social benefits which research hints that organized and instructive esports play may help accrue.

\section{Methods}

Our research fieldwork was conducted from December, 2017 through May, 2018. We used a combination of qualitative methods, including: school-site observations at League-participating high schools during after-school practices; observations during the culminating championship events; focus groups with League players at their high schools toward the end of or after League play was finished; focus groups with coaches through the online platform Discord after League play was finished; focus groups with League GMs (teachers who were in charge of the team) also through Discord after League play was finished; and brief interviews with parents at the championship events. We also observed one training meeting with League GMs in December 2017, three online meetings with League leadership and their esports community advisory board, and six in-person half-day workshops for students across the program on Saturday mornings at the Santa Ana Esports Arena.

We conducted fieldwork at six League-participating school sites, selected for maximum geographic, income, and racial/ethnic variation across Orange County. Though we cannot list comprehensive demographic statistics of these six schools due to identifiability restrictions, they varied greatly in terms of economic status (from under $15 \%$ of students qualifying for free or reduced lunch to over 70\%), geography (evenly split between North and South county, a more affluent region), and race/ethnicity (including schools in which the largest populations were Hispanic, White, or Asian). None of our research sites had a significant African American population (see "Equity," 5.2). Our research plan at school sites involved several phases: an introductory visit, which included an explanation of our project and goals and the bounds of the study; a second visit, which was a non-interview observation during team practice matches; a third visit, which was a focus group with the student League team players. One school had meeting space conflicts after standardized testing began and was unable to provide access to students after our first visit, leaving practice observation and focus group at five total schools.

Throughout this process we aimed for ethnographic best practices in data collection: jottings during observations and focus groups for recall and detail; as-soon-as-possible write-up of jottings into field notes from each visit [11]; a separate component in field notes on researcher reflections and emergent trends as the fieldwork progressed [13]. Focus groups were conducted in person with student team members at their school sites and lasted approximately 45 minutes [33]. There was no incentive given for participation. These followed a semi-structured protocol inspired by our two research questions and were audio recorded. Focus groups with coaches and GMs (teachers) were conducted over the audio gaming chat platform Discord and were also audio recorded. GMs and coaches were recruited for participation in focus groups from the entire League personnel, including as well as beyond our six school fieldwork sites. These focus groups also followed a semi-structured protocol and lasted between 45 minutes and two hours. In order to maximize recruitment from across the League, GMs and coaches were given a \$30 gift card incentive for their participation in these focus groups. In total, we gathered: 
- Approximately 20 hours of field observations of school teams

- Approximately 18 hours of field observations in student weekend workshops

- Focus group interviews with participating students ( $\mathrm{n}=39$; 35 male, 4 female)

- Focus groups with League GMs (n=11), including one Asst. Principal

- Focus groups with Coaches $(\mathrm{n}=5)$

- Interviews with parents of participating students at the championship event $(\mathrm{n}=10)$

We did not collect race/ethnicity data for individual research participants. All interviews and focus groups were transcribed. These transcriptions as well as the field notes were uploaded to the qualitative/mixed-methods data analysis platform Dedoose. For the purposes of this paper, with its emphasis on League logistics and the preliminary identification of indicators of learning potential, we base our findings on our collaborative discussions of field notes and read-throughs of all transcripts. Our team is currently performing an in-depth systematic coding process of these data using a code tree aligned with Chuek's framework of overlapping standards for STEM and English/Language Arts to surface systematic evidence of learning, geared toward a contribution to the learning sciences at a later date [5]. The findings we present here may be viewed as guideposts from an exploratory standpoint alongside directional suggestions for further research regarding specific learning outcomes in this nascent space.

\section{Findings}

\subsection{RQ1: Programmatic and Operational Successes \& Pain Points}

\subsubsection{Getting the League Off the Ground}

The League was organized by stakeholders from the Orange County Department of Education, the UC Irvine collegiate esports program, Connected Camps (an informal learning organization that supplied coaches), and the Samueli Foundation in the Spring and Summer of 2017. An open call circulated to all high schools in the region as an invitation to those schools to form esports teams. Components of the endeavor included general managers or "GMs," which were school-site teachers, often those who taught classes in computer science, audio/video production, or graphic design, who would manage the team's schedule and practices. Each GM could apply to have their team coached throughout the season by experienced "diamond-level” League of Legends players supplied and managed through Connected Camps. The teams themselves were comprised of five student players to a team and one alternate (some schools fielded two teams). The League also organized a series of online, via Discord, weekend instructional clinics facilitated by Connected Camps, in addition to six in-person Saturday morning workshops on various topics in esports. These were open to all interested students and hosted by UCI Esports. All students were required to obtain parent or guardian permission to participate in the League and maintain a minimum GPA of 2.0 and have no "N" or "U" marks in school citizenship. A training was conducted in December 2017 by League leadership for GMs as an on-boarding to the game and a run-through of logistical and technical issues. Team sign-up deadlines were in December 2017. Practice began January 2018 and official League tournament play began February 2018, with playoffs and championships in April 2018.

In order to participate, a school had to agree to provide a minimum a set of resource standards including computers and intangible tools like internet access. The GM (teacher) needed to find a room with computers to host practices, which were on campus and required players to be co-located in the same space. Often this was their own room, as many were digital media production / computer teachers, but in some cases they were enthusiastic teachers who did not have access to computers and therefore partnered with a teacher who was in charge of a space with computers. In practice this didn't always pan out. One school, for example, didn't officially form a "club” on campus (see section 5.1), and thus could not reserve space on campus. Although the League officially required all teams to practice in person after school at the school site, they ended up going to a local game café to practice.

The GMs also needed to get permission to install League of Legends on their school's computers as well as get permission to disable the IT firewall that hindered online play. Usually this was done at the district level. Some GMs were able to find allies in upper-level school administration to help convince district leadership to do so. Even if GMs convinced their school and district admin to install the game, this varied widely on the ground. School 1 only took down the firewall for 2.5 hours in the afternoon. School 2 mostly practiced from home because computers were slow at school and their personal peripherals were better. Similarly, as an organizing partner, UCI Esports was able to use their established relationship with Riot Games to arrange for participating schools with static IP addresses to be given access to an unlocked roster of all champions to play; however, some schools were not able to do this due to technical constraints and some students ended up using their personal in game resources (pre-purchased and in game currency) to obtain an ideal stable champions to play (see "Equity," $5.2)$.

Though some schools had these start-up headaches, some were poised to integrate the opportunities of the League from day one. One GM explained, "I guess almost two years ago now, I had two of my students come up and said they wanted to form an esports club, two young ladies. And so, they were very persistent and they were very organized and so this is the second year now that we've had our esports club and the beauty of that was that I already had all the software installed, I already had the lab set up...And so, when my principal said 'Hey, OC Department of Ed is starting a competition between schools,' I was very excited about that and the young ladies that formed the club, that was their dream essentially, that they were hoping that there would be some way that we could play against other schools." Accordingly, each school site handled recruitment and try-outs differently based on a combination of 
The Building Blocks of an Educational Esports League: Lessons From Year One in Orange County High Schools

existing assets, student expertise, and administration support (see Section 5.1 for an example of a difficult try-out scheme).

\subsubsection{Coaching}

Coaches, who were seasoned "diamond-level” League of Legends players and who generally coached teams at multiple schools, expressed frustration with the wide spectrum of quality of connection, computers, and peripherals at different sites. This ranged from slow ping rates to slow computers (and laptops) to low-quality peripherals. One coach described League of Legends as a "feel game," meaning competitive-level players rely on body/muscle memory and the feel of very responsive keyboards and the like, which is why many competitive players bring their own peripherals to matches. This, combined with a lack of robust "club" infrastructure, resulted in heavy momentum for several teams to move away from practicing at school and to practice and compete from home - in their eyes, the drawbacks to practicing on campus, co-located, outweighed the benefits.

Coaching varied widely. At School 2, with a GM with no game knowledge, the coach (who was also local) did heavy lifting on ingame training, met with the team in-person, and also helped manage scheduling and even discipline. At another school with a game-knowledgeable GM, the coach (who was remote) was viewed as not very useful and the GM, who had preexisting experience with League of Legends, did a lot of training. Additionally, at least one school did not take advantage at first of the coaching opportunity, believing that their teams were already quite good and did not need that training component. That GM explained, "Looking back now, I wish I had taken more advantage of the workshops and the coaching. I originally came out of this kind of like, 'We've already got our club and we're not interested in a bunch of training or anything like that. We just want to play.'”

Since GMs were usually teachers who had little to no experience with League of Legends or other competitive videogames, the bulk of the teaching - of game-specific skills as well as socio-emotional skills such as teamwork and avoiding "tilt," and communication skills - came from coaches. One student at School 4 told us, "I think [our coach] helped us to like, be more like introspective to like look at ourselves and try to see what we were doing incorrectly. He also like, helped us kind of control our own toxicity.” In focus group, coaches told us they did a lot of figuring out roles and responsibilities with school site GMs at the beginning of the League-sometimes both parties weren't really sure what the other was supposed to be responsible for (such as scheduling and discipline/rule enforcement).

\subsubsection{Issues of Play}

The most-often repeated pain point for GMs, coaches, and students was match scheduling. In this inaugural season, Wednesday afternoons were the default match time each week for competitive league play. However, many of the GMs and students we spoke with revealed that this rarely, if ever, was the actual time they played. This was due to a number of factors such as students having other commitments such as tennis or swimming or GMs not being communicative with other GMs in a timely fashion.

The schools we observed varied widely in terms of pre-existing student proficiency in League of Legends. Some students on the teams at School 3 (at which over $70 \%$ of the student body qualifies for free or reduced price lunch) told us they didn't have PCs at home at all and that this season was the first time they had ever played League of Legends, doing so entirely at the school's computer classroom. Though they were upbeat in our focus group, they expressed frustration at constantly losing to better teams, which sometimes included behavior called "BM," or "bad mouthing" or "bad manners," in which the winning team would taunt the losers in-game. A GM at another, non-field site school, explained: "We were in the lower third so it got frustrating for the kids getting pounded by the higher teams so is there some thought process of trying to break into different leagues based on level like they do with academic decathlon and things like that where there's this group and this group and this group and just ways of making it more competitive within their level.”

This was an inconvenience at best and resulted in contentious situations at worst. The GM at School 4, who felt they were quite accommodating of schedule changes, was upset at a lack of reciprocity: "[Our players] have been so good about being flexible, because there were some schools that were pretty rude to us about not being flexible even though we've always been flexible...and like, we could have just said 'No' to everybody and just won automatically." A GM at a non-field-site school told us that one week's match scheduling communication exchange resulted in a student from the opposing team bad-mouthing them over Discord. GMs also told us that, when down to the wire, they would resort to email and phone to reschedule matches as they could not be sure that other GMs would check Discord regularly. Nevertheless, despite some awkward instances, GMs and other participants expressed general optimism and willingness to "put up" with this pain point because they understood that they were part of the inaugural season and organizational kinks needed to be worked out and they remained committed to students to make this happen on a weekly basis. Several participants also wondered how the League could incorporate face-to-face time between competing schools at strategic points during the season, such as at launch, or with some sort of closure activity. As it was, several GMs were disappointed in the lack of closure throughout the league, even if their teams made it to the quarter-finals and championships.

Though we did not extensively observe in-game play, we asked about disruptive game behaviors during our focus groups and jotted any hints of it during our observations. The League created an extensive 18-page code of conduct modeled after the free version found at http://esportcodeofconduct.com/ with distinct recommendations and rules for players, supervisors, and parents 
that all players had to agree to in order to be eligible to participate. Nevertheless, we did hear about "BM" ("bad mouthing" or "bad manners") that would fly under the radar of observing GMs, especially GMs that were not conversant in the nuances of League of Legends. We heard about one instance in which an entire team was punished by match forfeiture when an opposing team reported unsportsmanlike behavior, which was then investigated by the corresponding coaches, GMs, and League administration. When we went back to observe that team after our first visit, they appeared much more controlled in their banter during practice and even referenced this incident, with one player saying to his teammates, "Hey, calm down, we don't want another [incident]."

\subsubsection{The Support Role of In-Person Workshops and Online Clinics}

Over six weekends, UCI's esports program hosted a series of workshops on building one's own PC, analyzing and improving one's game, shoutcasting, streaming tournament planning and healthy gaming. Each three-hour workshop drew a group of approximately 13-20 students. Workshops were designed by the esports research lab at UCI in concert with personnel from the UCI Esports Arena, organized by the Orange County Department of Education, and taught by esports professionals across the local industry (e.g. collegiate team players, coaches, shoutcasters, or arena staff) relevant to each week's topic. No formal assessments were used, but observations at the events indicated that students were most engaged with hands-on activities that allowed them to actively take part in the given esports activity and then receive feedback from an expert. For example, students were very receptive to receiving feedback on their play choices from the collegiate team players and coach and were excited about shoutcasting over a match with an expert shoutcaster. This inaugural year, not all esports experts leveraged for the workshops were experienced or trained in working with high school youth.

Throughout the full tournament activity season, Connected Camps hosted online weekend clinics Friday evenings and Saturdays via Discord. The topics were broad across the esports domain and had participation ranging from 1-30 students. Some were focused on gameplay skills for specific in-game roles like "Jungler". Others focused on team composition and statistical analysis across the game. Some were designed to teach skills like shoutcasting, or creating Twitch channels in support of live streaming gameplay. Coaches reported at the early part of the season that these clinics were overfull and the sessions were difficult to manage. Coaches met weekly via Discord to reflect and iterate their curriculum and respond to current issues, modifying their content and approach each week as the needs and number of students fluctuated.

While no fees were charged for participating in the online clinics or in-person workshops, inclusion assumes an individual wealth of tangible and intangible resources. The online clinics assume access and availability of a device running Discord, an internet connection, in addition to a quiet, safe space to tune-in and engage at the meeting time; the in-person workshops assume transport for the 15- to 17-year-old attendees to UCI either for drop-off and pickup or to park in the lot and pay the daily fee.

\subsection{RQ2: Potential Alignments Between the Esports League and Learning}

\subsubsection{Preliminary Suggestions of Educational Benefits}

Though League leadership did not scaffold explicit learning opportunities into tournament play, we witnessed organic, unprompted efforts and ideas from educators to develop knowledge in specific disciplinary STEM and ELA areas. We believe there is ample space here for much more structured alignment between esports high-school play and standards-based learning across STEM, ELA, and technical education (ISTE). For example:

- $\quad$ At School 6, the GM tasked students with producing their own website for their school's team.

- At School 1, the students have taken it upon themselves, with the support of their GM, to edit in-game video clips and make mini movies for their school's TV station.

- At School 4, the GM and coach gave homework assignments on learning various champions' strengths and weaknesses and reporting back, such as screencapping the game load screen and analyzing the pros and cons of team composition. Also, students decided on their own gamerelated topics for learning and self-directed several lessons (such as “improving your 'creep score'”).

- $\quad$ One GM, who is a computer science teacher, commented: "The things that popped into my head include things like doing animations that could be incorporated in the games. Maybe creating a map, programming it, you know. We could write patches for it or we could write mods for the game. Just for what I teach, that's what comes up."

- The GM at School 1, who is in charge of digital production at his school, stated: “As I'm walking around the room as they're playing, I'll see their notebooks chock-full of drawings and some of them have League of Legends drawings. There's another reason to bring in the STEAM [in addition to STEM] part of it."

- League of Legends appears to encourage critical attention and analysis. One student at School 3 told us that the pick and ban process of choosing characters during the opening moments of a match translated directly into the kind of communicative logic they use in class debates elsewhere. Another student at School 3 explained, "Comparatively to like other games that I've played, I've never really analyzed a game more closely than I have with League. Mostly because of my coach."

At several of our field sites we observed marked changes in how students on the competitive teams communicated in-game from the beginning of the season to the end. Students were much more communicative during game play by League's end, adopting proactive communication strategies of shotcalling and anticipatory analysis, support/morale statements, and self-prompted reflexive 
The Building Blocks of an Educational Esports League: Lessons

From Year One in Orange County High Schools

communal team analysis after a match concluded regarding what worked and what didn't. This suggests potential for amplification and alignment to several core overlapping STEM and ELA standards, including: "Engage in argument from evidence"; "Construct viable arguments and critique reasoning of others"; and "Obtain, evaluate, and communicate information" [5]. A student at School 2, when asked about what they thought they got out of playing in the League, explained: "I think communication. [Our coach] really stressed communication as a team, and then I think we've all improved on like communicating with each other, confidence with each other."

GMs also reported an increase in communication skills in their students and even an occasional increase in engagement in school and teacher-student bonding. One GM explained: “I've definitely seen them grow a lot over the course of the time I've met them because my first time meeting them was when they showed up to the meeting because I never had them as students except one of them. One that I've had as a student, she's definitely blossomed a lot. Like she's definitely more engaged in class." We should emphasize, however, that we did not measure any learning outcomes or school engagement quantitatively, as our research effort in this phase was formative, directional and exploratory (see suggestions for further research in section 5.3).

\subsubsection{Social and Emotional Learning}

Students, GMs, and coaches gave us testimony that student social and emotional learning occurred among team players as the season progressed. Key components of this learning appeared to align with CASEL standards, including: self-management, social awareness, relationship skills, and responsible decision-making. One student at School 3 gave us his evaluation of how he changed over the course of the season: "I feel like me personally, like I've become a lot more calm as a person. I've learned to like, not get angry when you're doing something or you or your team messes up. Before, I would be playing on console [not League] and I would get mad at myself if I was doing bad or something and now I'm like, 'Oh, you know what, it's a team game. I let down my team but at the end of the day they're still ok.' I've learned a lot to just keep cool during the game and be ok with losing or winning."

A student at School 4 had a similar reflection on what he learned from being on the competitive League of Legends team at his school: "I feel like you really need to understand how like, how another person would feel about their own mistakes and really say something in a nice way and not go so, you know, off the charts with it, and really get off like, 'Hey, this would help and this and that.' Like, just be nice about it, and not just be like, grr, you know." Another student at the same school on the team explained, "In the beginning of all this, I was like, if we lose like the game, I was like, 'Okay, we lose because someone else falls.' Now, like, 'Okay, we lose together, or we win together.' You know, like teamwork.” At the same time, students developed strategies to cope with "BM": "bad-mouthing” or "bad manners" such as having in-game taunting or avatar dancing before landing a killing blow happened, and not to get "tilted" or overly upset. In fact, in their conversations with us, League players seemed to view the ability to refrain from disruptive behaviors as a positive indication of team-oriented professionalism and seemed to "look down" on that behavior as an amateurish tendency. However, as stated above, we did not heavily observe in-game play and can't confirm this actually was the case during play. Nevertheless, we believe there are strong indications that SEL could be a major focal point for learning in the relationship between esports and high schools.

\section{Discussion}

Here we provide reflection based on our interviews and observations, give general context to the findings, and surface issues of broader engagement and equity. We close with recommendations for future research.

One theme that emerged during our fieldwork was the shape of the life of today's high school students: extracurriculars/after-school activities are chosen early in the school year and strategically, both in terms of future opportunity (such as college resume building) and in terms of what already exists and is popular at that particular school. In other words, students' after-school lives are jam-packed and deciding what to devote one's time to is a complex negotiation. One student at School 4 told us, "We missed out on recruitment, like a lot of people had already joined orchestra or other afterschool stuff." Deciding where esports may or may not fit in this landscape is vital to the success of the endeavor on any particular campus.

GMs, across the board, expressed satisfaction and pride in completing this first season, as well as many frustrations in figuring out different moving parts as the League progressed. There was a strong call for more robust training and workshops for GMs. General Managers occupied a complex position: they were high school teachers who may or may not have access to school computers or be familiar with the games in play; they were oncampus boosters of esports to sometimes skeptical fellow faculty and administration; they were coordinators of League play (including the onerous task of scheduling matches each week); they were disciplinarians (which is difficult when they are not familiar with the game at all, making it hard to know when codes of conduct or game-specific rules are broken).

\subsection{The Role of Clubs}

Some schools already had or developed campus esports "clubs" that were not oriented toward competitive League play. Clubs accommodated more students than the 5-10 that were on the competitive teams at each school and generally supplied an environment akin to what Ito et al. identified as a space to "hang out, geek out, and mess around" [25]. Though the role of the club was not expressly articulated at the start of the League endeavor, we believe that it has great potential to intervene in issues of learning, equity, and continued engagement on campus with 
interested students. If navigated incorrectly, however, it also has the potential to alienate some students from the students on the competitive team.

In all six observed schools and also as related the testimony in our coach and teacher focus groups, initial recruitment events drew a wide swath of interested students, with a wide variety of experience and skill with League of Legends. We heard stories that, after the first session, a lot of students didn't return, either discouraged because they did not feel they already had enough skill at League of Legends and that it was the only game on offer, or that they did not pass try-outs. The students who "made it" into the teams after try-outs, and the teams that went on to play-offs, trended toward being made up of already experienced competitive players.

Clubs can provide a train-up function for students who are interested in potential competitive play but are not skilled enough to walk in the door and make the school's team. They can be spaces where multiple games are played informally, wrapping more students into team-based play and subsequent socio-emotional and communication skills as well as increasing diversity across race/ethnicity, socioeconomics, and gender. It is a way to involve non-competing students in learning experiences such as shoutcasting, statistical analysis, publicity, and management. They can be a means for continuing to engage students before League play officially starts and after it concludes.

Clubs are by definition student-led, which allows for more agency and requires students to collectively work to write a charter, elect officers, interface with the campus, and the like. The GM at School 1, for example, explained, "The jewel of all this would be the club itself, you know. Not all the kids are going to be able to compete so we're working with a couple kids, five or six [on the team]." He went on to cite other clubs at his school, such as Key Club or National Honors Society as "juggernauts" on campus, meaning that they magnetize students and give them a reason to be invested in school - and he hoped that the esports endeavor could do the same. At some schools, clubs or sports even come with student elective credit units.

However, at one school site, we saw friction between an alreadyestablished esports club and the new League play endeavor for this season. When the League was announced in the Fall of 2017, the esports club members reacted enthusiastically, taking it upon themselves to organize try-outs and form the competitive campus team. However, when the League coach first arrived, he reviewed the try-out data and realized that there were several excellent players that were not part of the club; they had tried out, but not been invited to be on the team. The coach ordered new try-outs, forming a team of players that he believed were the best. This alienated the existing club organization and, as the school year wound down, there still had been no substantial reconciliation between the two entities. Any endeavor to institute a competitive esports team on a campus should be aware of the pre-existing landscape and involve coaches from the start, with transparent guidelines and expectations about competitive team composition.

\subsection{Parent Engagement and Student Relationship to School}

Though we did not systematically interview parents for this formative evaluation, we did ask all student focus group participants about their parents' opinions of their participation. We also approached parents who attended the championship events for short interviews on their opinions of their children's participation. According to the students, their parents by and large ranged from resistant to simply bewildered at the idea of competitive videogaming in schools. Some were outright hostile to the idea and the student had to artfully negotiate their involvement, guaranteeing certain amounts of time on homework or even vaguely promising "that it wouldn't get in the way of school." Many of the parents we spoke to directly at the tournamentadmittedly, a small and biased sample-were excited about the potential of colleges awarding scholarships for esports.

A student at School 3 told us a story about how his dad, very resistant initially and who rarely conversed with him in general, opened up to him throughout the course of the season: "My dad's like the man-man, your stereotypical guy, all buff, all sports, and I'm not really up to that. He was completely against technology. But I've opened my dad up a lot more to it. He's starting to watch Let's Plays now, in Spanish. I think it's changed my relationship with my parents a lot. [...] I think we've been more connected, soto-say."

Contrary to the assumption that videogames and school are oppositional, we heard testimony that, for some students, their involvement in the Esports League acted as a motivator to be more engaged in school. For one, there is the simple requirement of reaching a GPA and school citizenship/conduct threshold to be eligible for League play. But also, GMs expressed the general sentiment of the League being able to reach and involve kids who would normally not be invested in school spirit, or endeavors such as more traditional sports. One non-field-site school Assistant Principal lamented that they had a hard time activating school spirit in general, citing that, at the time of our interview, they had only sold approximately 30 tickets to the Spring Formal. However, he enthusiastically mentioned that their school's esports team captains drew more applause and cheers at the school's winter sports pep rally than the captains of traditional teams such as baseball or basketball, and that their League matches were streamed in the school cafeteria, with student crowds raucous and at capacity. Another GM at a non-field-site school explained, "The simple fact that they wanted to be-They're so excited about, 'I'm going to compete today after school and I heard my name on the announcements and I'm tied into the school now.' That gets them to show up. I think their attendance is going to go up. I think, you know, their investment in the entire school curriculum is going to go up." However, we did not collect attendance data and cannot systematically confirm this effect. 
The Building Blocks of an Educational Esports League: Lessons

From Year One in Orange County High Schools

\subsection{Equity}

We heard stories about how this esports endeavor enfranchised and empowered students who would not normally participate in "traditional" sports or other extracurriculars on campus, which we believe carries strong positive equity potential across a school site writ large. However, within the League and school teams themselves, we also got feedback that those students who were drawn to League of Legends, specifically, were ones who were somewhat more academically engaged overall, could tackle the high learning curve, and who came through the door with high-end home computer and internet access. We heard echoed several times the sentiment that the GM at School 1 told us early on: "League of Legends draws a certain kind of student." A different GM in focus group, using similar language, said, "More games for next year would attract more or an even different type of kid." For example, one way this manifested was the school info sessions and try-outs; if you didn't already know what you were doing in League of Legends, you probably wouldn't return.

This shorthand may also refer to gender, with the overwhelming majority of competitive players in this League being male, despite interest from girls such as described in Section 4.1.1. At two of our sites, our participants unanimously considered the sole girl on their competitive team to be their best player. Moving forward, we believe that efforts to achieve gender parity in future endeavors of this sort are essential, including proactively utilizing the authority of League personnel to anticipate, attend to, and discourage instances of misogynist sociality. This is particularly important since literature reveals that girls especially can benefit from school sports in terms of social and emotional development [37]. Although we did not ask about it, this shorthand might also signal a desire for more diversity in team composition terms of race/ethnicity and socioeconomic status. School 3, a low-income school, was ranked very low in the League's standings by season's end and, not coincidentally, was comprised of many kids who did not have League of Legends access or even computers at home and who were first introduced to the game during League play. Also, as noted above, though League of Legends is free to play, access to all playable champions requires in-game purchases; many students relied on their personal accounts to do this. Racially and ethnically, due to the demographic history of Orange County (part historical Hispanic community, part “white-flight” suburb of Los Angeles, with a major post-1965 Asian immigrant population), the deployment of the League in this region by default did not include many African American students. Given the potential benefits suggested in this paper, we believe porting this endeavor to other school districts could have significant impact on diverse populations.

We believe that one solution within participating schools to engage more diverse students from a gender, race/ethnicity, and socioeconomic standpoint could be to leverage the "club" structure in order to increase access and equity. As a student at School 3 commented, on having a more robust club with more students involved: "I think it would create a better environment, not just for the team, but for everyone. You would get to talk to a lot more people. I feel like it would be a good way to be more social." We also believe that opening up competitive and club play to more and different types of games could address issues of equity that arise from differences in at-home access and background in gaming. The club, in combination with weekend workshops that were open to any student (not just League players), could be used to train up students who may be eager and talented but lack home resources, support, or pre-existing game training.

\subsection{Suggestions for Further Research}

This first-year, exploratory investigation revealed possibilities for further investigation into the potential alignments between esports and learning. However, more systematic research is needed to generate concrete proof of learning outcomes. Specifically, we suggest that research closely investigate possible positive or negative connections between the esports in the high school setting and attendance, motivation, homework, and academic performance. We saw strong potential for social and emotional learning; this should be another arena for further research, especially in context of the literature on the benefits of "regular" athletics and other extracurriculars in school settings. We suggest investment in building out specific standards-based exercises and opportunities that span the scope of competitive play teams as well as clubs - the sorts of exercises we saw committed teachers, who instinctually may capitalize on play as a learning opportunity, generate spontaneously for their students during the season. Accordingly, we also envision assessment metrics based on these standards which can be used as opportunities to demonstrate and practice learning while serving as assessment points to share with schools as positive evidence for the role of video games in learning.

\section{Conclusion}

Our exploratory research revealed indications that there is potential for learning across several domains for esports in high schools. We heard particularly compelling testimony about social and emotional learning from teachers as well as students themselves. Nevertheless, more systematic assessment is needed to prove these outcomes. We also offered a detailed look at how this League got up-and-running, logistically, with many different moving pieces. We hope that readers may heed these specifics should they have interest in this type of endeavor in their own educational context.

\section{ACKNOWLEDGMENTS}

This research was funded by the Samueli Foundation.

\section{REFERENCES}

[1] Adinolf, S. and Turkay, S. 2018. Toxic Behaviors in esports Games: Player Perceptions and Coping Strategies. Proceedings of the 2018 Annual Symposium on Computer-Human 
Interaction in Play Companion Extended Abstracts (New York, NY, USA, 2018), 365-372.

[2] Anthropy, A. 2012. Rise of the Videogame Zinesters: How Freaks, Normals, Amateurs, Artists, Dreamers, Drop-outs, Queers, Housewives, and People Like You Are Taking Back an Art Form. Seven Stories Press.

[3] Butryn, T. 2002. Cyborg horizons: Sport and the ethics of selftechnologization. Sport Technology: History, Philosophy and Policy. A. Miah et al., eds. Emerald Group Publishing Limited.

[4] Cavalli, E. 2009. U.C. Berkeley Now Offers StarCraft Class. Wired. Retrieved June 28, 2019 from https://www.wired.com/2009/01/uc-berkeley-int/

[5] Chuek, T. 2013. Relationships and convergences among the mathematics, science, and ELA practices. Refined version of diagram created by the Understanding Language Initiative for ELP Standards. Stanford University.

[6] Dicheva, D. et al. 2015. Gamification in Education: A Systematic Mapping Study. Journal of Educational Technology \& Society. 18, 3 (2015), 75-88.

[7] Dromi, P.G. and Krampf, Z. 1986. Programming Revisited. Social Work with Groups. 9, 1 (Jul. 1986), 91-106. DOI:https://doi.org/10.1300/J009v09n01_08.

[8] DuBois, D.L. et al. 2000. Self-System Influences During Early Adolescence:: Investigation of an Integrative Model. The Journal of Early Adolescence. 20, 1 (Feb. 2000), 12-43. DOI:https://doi.org/10.1177/0272431600020001002.

[9] Duncan, S.C. 2010. Gamers as Designers: A Framework for Investigating Design in Gaming Affinity Spaces. E-Learning and Digital Media. 7, 1 (Mar. 2010), 21-34. DOI:https://doi.org/10.2304/elea.2010.7.1.21.

[10] Eime, R.M. et al. 2013. A systematic review of the psychological and social benefits of participation in sport for children and adolescents: informing development of a conceptual model of health through sport. International Journal of Behavioral Nutrition and Physical Activity. 10, 1 (Aug. 2013), 98. DOI:https://doi.org/10.1186/1479-5868-10-98.

[11] Emerson, R.M. et al. 1995. Writing Ethnographic Fieldnotes. University Of Chicago Press.

[12] Fogel, S. 2018. High School esports Competitions to Begin in U.S. This Year. Variety.

[13] Foley, D.E. 2002. Critical ethnography: The reflexive turn. International Journal of Qualitative Studies in Education. 15, 4 (2002), 469-490. DOI:https://doi.org/10.1080/09518390210145534.

[14] Formative vs Summative Assessment - Eberly Center Carnegie Mellon University: https://www.cmu.edu/teaching/assessment/basics/formativesummative.html. Accessed: 2019-01-09.
[15] Freeman, G. and Wohn, D.Y. 2017. esports As An Emerging Research Context at CHI: Diverse Perspectives on Definitions. Proceedings of the 2017 CHI Conference Extended Abstracts on [16] Human Factors in Computing Systems (New York, NY, USA, 2017), 1601-1608.

[17] Freeman, G. and Wohn, D.Y. 2017. Social Support in esports: Building Emotional and Esteem Support from Instrumental Support Interactions in a Highly Competitive Environment. Proceedings of the Annual Symposium on Computer-Human Interaction in Play (New York, NY, USA, 2017), 435-447.

[18] Gee, J. et al. 2007. Social Linguistics and Literacies : Ideology in Discourses. Routledge.

[19] Granic, I. et al. 2014. The benefits of playing video games. American Psychologist. 69, 1 (2014), 66-78. DOI:https://doi.org/10.1037/a0034857.

[20] Hamari, J. and Sjöblom, M. 2017. What is esports and why do people watch it? Internet Research. 27, 2 (Mar. 2017), 211-232. DOI:https://doi.org/10.1108/IntR-04-2016-0085.

[21] Home - Collegiate esports Governing Body: https://nacesports.org/. Accessed: 2019-01-09.

[22] Hromek, R. 2004. Planting the Peace Virus: Early Intervention to Prevent Violence in Schools. SAGE.

[23] Hromek, R. and Roffey, S. 2009. Promoting Social and Emotional Learning With Games: "It's Fun and We Learn Things.” Simulation \& Gaming. 40, 5 (Oct. 2009), 626-644. DOI:https://doi.org/10.1177/1046878109333793.

[24] Ito, M. 2010. Hanging out, messing around, and geeking out : kids living and learning with new media. MIT Press.

[25] Ito, M. et al. 2013. Connected Learning: An Agenda for Research and Design. Digital Media and Learning Hub.

[26] Kapp, K.M. 2012. The Gamification of Learning and Instruction: Game-based Methods and Strategies for Training and Education. John Wiley \& Sons.

[27] Kovess-Masfety, V. et al. 2016. Is time spent playing video games associated with mental health, cognitive and social skills in young children? Social Psychiatry and Psychiatric

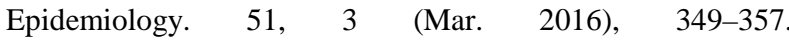
DOI:https://doi.org/10.1007/s00127-016-1179-6.

[28] League of Legends championships viewers 2018 | Statistic: https://www.statista.com/statistics/518126/league-of-legendschampionship-viewers/. Accessed: 2019-01-09.

[29] Lenhart, A. et al. 2008. Teens, Video Games, and Civics: Teens' Gaming Experiences Are Diverse and Include Significant Social Interaction and Civic Engagement. Pew Internet \& American Life Project.

[30] Mattinen, T. and Macey, J. 2018. Online Abuse and Age in Dota 2. Proceedings of the 22Nd International Academic Mindtrek Conference (New York, NY, USA, 2018), 69-78. 
The Building Blocks of an Educational Esports League: Lessons From Year One in Orange County High Schools

[31] Meet South Korea's High School esports Team: https://kotaku.com/meet-south-koreas-high-school-esportsteam-1766336052. Accessed: 2019-01-09.

[32] Moll, L.C. et al. 1992. Funds of Knowledge for Teaching: Using a Qualitative Approach to Connect Homes and Classrooms. Theory Into Practice. 31, 2 (Spring 1992), 132141.

[33] Morgan, D.L. 1996. Focus Groups as Qualitative Research, Second Edition. SAGE Publications, Inc.

[34] O’Callaghan, P.M. et al. 2003. Promoting social skills generalization with ADHD-diagnosed children in a sports setting. Behavior Therapy. 34, 3 (Jun. 2003), 313-330. DOI:https://doi.org/10.1016/S0005-7894(03)80003-5.

[35] Overwatch League comes to ESPN, Disney and ABC: 2018. http://www.espn.com/esports/story//id/24062274. Accessed: 2019-01-09.

[36] Patrick, H. et al. 1999. Adolescents' Commitment to Developing Talent: The Role of Peers in Continuing Motivation for Sports and the Arts. Journal of Youth and Adolescence. 28, 6 (Dec. 1999), 741-763. DOI:https://doi.org/10.1023/A:1021643718575.

[37] Pedersen, S. and Seidman, E. 2004. Team sports achievement and self-esteem development among urban adolescent girls. Psychology of Women Quarterly. 28, 4 (Nov. 2004), 412-422. DOI:https://doi.org/10.1111/j.1471-6402.2004.00158.x.

[38] Pew Research Center. 2015. Teens, Technology and Friendships.

[39] Report: esports To Grow Substantially And Near BillionDollar Revenues In 2018: https://www.forbes.com/sites/mattperez/2018/02/21/reportesports-to-grow-substantially-and-near-a-billion-dollarrevenues-in-2018/. Accessed: 2019-01-09.

[40] Resnick, M. 2018. Lifelong Kindergarten: Cultivating Creativity through Projects, Passion, Peers, and Play. Cambridge, MA: The MIT Press.

[41] Riot Games Reveals “League of Legends” Has 100 Million Monthly Players: https://www.forbes.com/sites/insertcoin/2016/09/13/riotgames-reveals-league-of-legends-has-100-million-monthlyplayers/. Accessed: 2019-01-09.

[42] Russoniello, C.V. et al. 2009. The Effectiveness of Casual Video Games in Improving Mood and Decreasing Stress. Journal of CyberTherapy \& Rehabilitation. 2, 1 (Spring 2009), 53-66.

[43] Sala, G. and Gobet, F. 2016. Do the benefits of chess instruction transfer to academic and cognitive skills? A metaanalysis. Educational Research Review 18: 46-57. https://doi.org/10.1016/j.edurev.2016.02.002
[44] Salen, K. and Tekinbaş, K.S. 2008. The Ecology of Games: Connecting Youth, Games, and Learning. MIT Press.

[45] Sanders, C.E. et al. 2000. Moderate involvement in sports is related to lower depression levels among adolescents. Adolescence; Roslyn Heights. 35, 140 (Winter 2000), 793-7.

[46] School esports Australia - esports for all School Age Children: https://esports.org.au/. Accessed: 2019-01-09.

[47] Scriven, M. 1967. The methodology of evaluation. Perspectives of curriculum evaluation. R.M. (Robert M. Gagne et al., eds. Rand McNally. 39-83.

[48] Seo, Y. and Jung, S.-U. 2016. Beyond solitary play in computer games: The social practices of esports. Journal of Consumer Culture. 16, 3 (Nov. 2016), 635-655. DOI:https://doi.org/10.1177/1469540514553711.

[49] Sheridan, M.K. and And Others 1995. Using the Supportive Play Model: Individualized Intervention in Early Childhood Practice. Teachers College Press, 1234 Amsterdam Ave.

[50] Steinkuehler, C. 2007. Massively Multiplayer Online Gaming as a Constellation of Literacy Practices. E-Learning and Digital Media. 4, 3 (Sep. 2007), 297-318. DOI:https://doi.org/10.2304/elea.2007.4.3.297.

[51] Steinkuehler, C. 2010. Video Games and Digital Literacies. Journal of Adolescent \& Adult Literacy. 54, 1 (2010), 61-63. DOI:https://doi.org/10.1598/JAAL.54.1.7.

[52] Steinkuehler, C. et al. 2012. Games, Learning, and Society: Learning and Meaning in the Digital Age. Cambridge University Press.

[53] Steinkuehler, C.A. 2004. Learning in Massively Multiplayer Online Games. Proceedings of the 6th International Conference on Learning Sciences (Santa Monica, California, 2004), 521528.

[54] The New London Group 1996. A Pedagogy of Multiliteracies: Designing Social Futures. Harvard Educational Review. 66, 1 (Apr. 1996), 60-93. DOI:https://doi.org/10.17763/haer.66.1.17370n67v22j160u.

[55] Velez, J.A. et al. 2016. Violent Video Games and Reciprocity: The Attenuating Effects of Cooperative Game Play on Subsequent Aggression. Communication Research. 43, 4 (Jun. 2016), 447-467. DOI:https://doi.org/10.1177/0093650214552519.

[56] Wagner, M.G. On the Scientific Relevance of esports. International Conference on Internet Computing. 2006.

[57] Witkowski, E. 2012. On the Digital Playing Field: How We "Do Sport" With Networked Computer Games. Games and Culture. $\quad 7, \quad 5 \quad$ (Sep. 2012), 349-374. DOI:https://doi.org/10.1177/1555412012454222. 